\title{
Inference on Forward Exchange Rate Risk Premium: Reviewing Signal Extraction Methods
}

\author{
Ramaprasad Bhar* \\ School of Banking and Finance \\ The Australian School of Business \\ The University of New South Wales \\ Sydney 2052, AUSTRALIA \\ Email: R.Bhar@unsw.edu.au \\ Carl Chiarella \\ School of Finance and Economics \\ University of Technology, Sydney \\ PO Box 123, Broadway, NSW 2007 \\ AUSTRALIA \\ Email: carl.chiarella@uts.edu.au
}

* Corresponding author: 


\title{
Inference on Forward Exchange Rate Risk Premium: Reviewing Signal Extraction Methods
}

\begin{abstract}
:
The efficacy of forward exchange rate as an unbiased predictor of future spot exchange rate has been the subject of research for many years. However, observed deviation from this hypothesis has been attributed to the existence of risk premium in the forward exchange rate. In this article we review two methodologies proposed in the literature for inferring this unobserved risk premium. Both these approaches rely on signal extraction mechanism with a basic difference in setting up the framework. The more recent approach uses the derivatives pricing principle that relates the historical and the risk neutral measures with a suitable specification of the market price of risk. The earlier approach directly specifies the risk premium in the historical measure. We compare these two methods in term of their ability to predict spot exchange rate one step ahead and contrast these with that of random walk forecast.
\end{abstract}




\section{Introduction}

Several regression based studies attempted to explain the ability (or otherwise) of the forward exchange rates in predicting the future realised spot exchange rates. Although with the improvements in econometric theory the nature of the tests employed have changed, but the basic approach has remained essentially within the regression framework. For example, Wu and Zhang (1997) employ a non-parametric test and not only reject the unbiasedness hypothesis but also conclude that the forward premium either contains no information or wrong information about the future currency depreciation. On the other hand, Bakshi and Naka (1997) derive an error correction model under the assumption that the spot and the forward rates are cointegrated and conclude using the generalised method of moments that the unbiasedness hypothesis cannot be rejected. Phillips and McFarland (1997) develop a robust test and reject the unbiasedness hypothesis but conclude that the forward rate has an important role as a predictor of the future spot rate.

The failure of the unbiasedness hypothesis has been attributed to the existence of a foreign exchange risk premium. This has led to a great deal of research on the modelling of the risk premia in the forward exchange rate market. However, models of risk premia have been unsuccessful in explaining the magnitude of the failure of unbiasedness (Engel (1996), page 124). We define the term $\mathrm{rp}_{\mathrm{t}} \equiv \mathrm{f}_{\mathrm{t}, \mathrm{k}}-\mathrm{E}_{\mathrm{t}}\left(\mathrm{s}_{\mathrm{t}+\mathrm{k}}\right)$ as the foreign exchange risk premium. Under risk-neutrality the market participants would behave in such a way that $f_{t, k}$ equals $\mathrm{E}_{\mathrm{t}}\left(\mathrm{s}_{\mathrm{t}+\mathrm{k}}\right)$ and the expected profit from forward market speculation would be zero. Stulz (1994) discusses a model of foreign exchange risk premium based on optimising behaviour of international investors. However, alongside such theoretical developments pure time series studies of $\mathrm{rp}_{\mathrm{t}}$ have also assumed a renewed importance. These are useful in describing the behaviour of $f_{t, k}-E_{t}\left(s_{t+k}\right)$. Models of the foreign exchange risks premium that assume rational expectations should be able to explain the observed time series properties. Examples of such studies include Backus et al (1993) and Bekaert (1994).

Modelling of the time varying risk premia has been inadequately addressed in the literature since there is little theory to guide us in this respect. Wolff (1987) and Cheung (1993) have modelled the risk premia as an unobserved component and estimated it using the Kalman filter. In their signal extraction approach they empirically determine the temporal behaviour of the risk premium using only data of forward exchange rate and the spot 
exchange rate. Although the signal extraction approach avoids specifying any particular form of the risk premia, it offers little insight into the risk premia and other economic variables. Cheung (1993) links the estimated risk premia with other macro economic variables. This relies on the inter-temporal asset-pricing model of Lucas (1982). However, the results are not very encouraging and the estimated regression models have very low R-squares.

Both Wolff (1987) and Cheung (1993) analyse the quantity $\left(\mathrm{f}_{\mathrm{t}, \mathrm{k}}-\mathrm{s}_{\mathrm{t}+\mathrm{k}}\right)$ to determine the time series characteristic of the unobserved risk premia. This in turn determines the dynamics of the unobserved component, the risk premia. For different currencies they examine the dynamics of the risk premia can be captured by a low order ARMA process. Wolff (2000) further extends the number of currencies studied in the same framework. In those papers, therefore, the observed difference between the forward exchange rate at time $t$ for the period $t+k$ and the subsequently realised spot rate at time $t+k$ is the main driver for the structure of the risk premia. This is assumed to be composed of the unobserved risk premia and the unexpected depreciation of the exchange rate. The complete model is, thus, specified in the historical measure.

Bhar, Chiarella and Pham (2001) propose an alternative approach to this problem of unobserved risk premium. They model the market price of risk (and hence the risk premia) by utilising the no-arbitrage relation between the spot and the forward markets. This requires an assumption about the dynamic process for the market price of risk. Then the dynamic system involving forward rate, spot rate, interest rates and the market price of risk could be cast into the state space model framework. The system is then estimated by Kalman filter. This approach fundamentally differs from those of Wolff (1987) and Cheung (1993) in that it models the spot and forward dynamics as well as the market price of risk which relates the historical and the risk-neutral measures. This approach can also be extended to foreign exchange options, which are a rich source of untapped information about markets' view of risk premia.

Both these approaches to estimating forward exchange rate risk premium are applied to a set of exchange rate data and the results compared. Since both these models rely of filtering and one step ahead prediction, we are able to compare this prediction of spot exchange rate with a random walk model. Both these approaches predict one step ahead spot exchange rate better than a random walk model.

In the next section we describe the essential features of these two approaches before discussing the empirical results. 


\section{Approach Based on Bhar, Chiarella and Pham (2001) (BCP Model)}

Let the spot exchange rate follow the one-dimensional geometric diffusion process,

$$
\mathrm{dS}=\mu \mathrm{Sdt}+\sigma_{\mathrm{S}} \mathrm{SdW}(\mathrm{t})
$$

where $\mu$ is the expected return from the spot asset, $\sigma_{\mathrm{S}}$ is the volatility of this return, both measured per unit of time and $\mathrm{dW}$ is the increment of a Wiener process under the so-called historical (statistical) probability measure $\mathrm{Q}, \mathrm{r}$ is the domestic risk-free interest rate and $\mathrm{r}_{\mathrm{f}}$ as the counterpart in the foreign currency. Since $r_{f}$ can be interpreted as a continuous dividend yield, the instantaneous return to an investor holding foreign exchange is $\left(\mu+r_{f}\right)$. Thus the relationship between the excess return demanded and the market price of risk $(\lambda)$ may be written

$$
\left(\mu+r_{f}\right)-r=\lambda \sigma_{s} \text {, or } \mu=\left(r-r_{f}\right)+\lambda \sigma_{s}
$$

Thus, under the historical measure Q equation (1) can be rewritten

$$
\mathrm{dS}=\left(\mathrm{r}-\mathrm{r}_{\mathrm{f}}+\lambda \sigma\right) \mathrm{Sdt}+\sigma_{\mathrm{S}} \mathrm{SdW}(\mathrm{t}) \text {, under } \mathrm{Q} \text {. }
$$

Alternatively under the risk neutral measure $\tilde{Q}$ the last equation becomes

$$
\mathrm{dS}=\left(\mathrm{r}-\mathrm{r}_{\mathrm{f}}\right) \mathrm{Sdt}+\sigma_{\mathrm{S}} \mathrm{Sd} \tilde{\mathrm{W}}(\mathrm{t}) \text {, where, } \tilde{\mathrm{W}}(\mathrm{t})=\mathrm{W}(\mathrm{t})+\int_{0}^{\mathrm{t}} \lambda(\mathrm{u}) \mathrm{du}
$$

We recall that under $\tilde{Q}$, the process $\tilde{W}(t)$ is not a standard Wiener process since $\mathrm{E}[\mathrm{d} \tilde{\mathrm{W}}(\mathrm{t})]=\lambda \mathrm{dt} \neq 0$ in general. However, Girsanov's theorem allows us to obtain the equivalent measure $\tilde{Q}$ under which $\tilde{W}(t)$ does become a standard Wiener process. The measures $\mathrm{Q}$ and $\tilde{\mathrm{Q}}$ are related via the Radon-Nikodym derivative. 
Using standard arguments for pricing derivative securities (see for example, Hull (1997), chapter 13), the forward price at time $t$ for a contract maturing at $\mathrm{T}(>\mathrm{t})$, is

$$
\mathrm{F}(\mathrm{t}, \mathrm{T})=\tilde{\mathrm{E}}_{\mathrm{t}}\left(\mathrm{S}_{\mathrm{T}}\right)
$$

But from equation (4), by Ito’s lemma,

$$
\mathrm{d}\left[\mathrm{S}(\mathrm{t}) \mathrm{e}^{-\left(\mathrm{r}-\mathrm{r}_{\mathrm{f}}\right) t}\right]=\sigma_{\mathrm{S}} \mathrm{S}(\mathrm{t}) \mathrm{e}^{-\left(\mathrm{r}-\mathrm{r}_{\mathrm{f}}\right) t} \mathrm{dW}(\mathrm{t}),
$$

so that under $\widetilde{Q}$, the quantity $\mathrm{S}(\mathrm{t}) \mathrm{e}^{-\left(\mathrm{r}-\mathrm{r}_{\mathrm{f}}\right) t}$ is a martingale and it follows immediately that

$$
\tilde{E}_{t}\left(S_{T}\right)=S_{t} e^{\left(r-r_{f}\right)(T-t)} \text {, i.e. } F(t, T)=S_{t} e^{\left(r-r_{f}\right)(T-t)} \text {. }
$$

If the maturity date of the contract is a constant period, $x$, ahead then (6) may be written as

$$
F(t, t+x)=S_{t} e^{\left(r-r_{f}\right) x}
$$

Then from (3), (4) and (7) and by a trivial application of Ito's lemma we obtain the stochastic differential equation for F under Q and $\tilde{Q}$. Thus, under $\tilde{Q}$

$$
\begin{aligned}
& \mathrm{dF}(\mathrm{t}, \mathrm{x})=\left(\mathrm{r}-\mathrm{r}_{\mathrm{f}}\right) \mathrm{F}(\mathrm{t}, \mathrm{x}) \mathrm{dt}+\sigma_{\mathrm{S}} \mathrm{F}(\mathrm{t}, \mathrm{x}) \mathrm{dW}(\mathrm{t}) \text {, whilst under } \mathrm{Q}, \\
& \mathrm{dF}(\mathrm{t}, \mathrm{x})=\left(\mathrm{r}-\mathrm{r}_{\mathrm{f}}+\lambda \sigma_{\mathrm{S}}\right) \mathrm{F}(\mathrm{t}, \mathrm{x}) \mathrm{dt}+\sigma_{\mathrm{S}} \mathrm{F}(\mathrm{t}, \mathrm{x}) \mathrm{dW}(\mathrm{t}) \text {, with, } \mathrm{F}(0, \mathrm{x})=\mathrm{S}_{0} \mathrm{e}^{\left(\mathrm{r}-\mathrm{r}_{\mathrm{f}}\right) \mathrm{x}} .
\end{aligned}
$$

We now assume that under historical measure $\mathrm{Q}$ the market price of risk, $\lambda$, follows the mean reverting stochastic process

$$
\mathrm{d} \lambda=\kappa(\bar{\lambda}-\lambda) \mathrm{dt}+\sigma_{\lambda} \mathrm{dW}
$$

where $\bar{\lambda}$ is the long-term average of the market price risk, $\kappa$ defines the speed of mean reversion. Here, we assume that the same noise process drives both the spot exchange rate 
and the market price of risk. It would of course also be possible to consider a second independent Wiener process driving the stochastic differential equation for $\lambda$. However, we leave investigation of this issue for future research.

It should be pointed out here that when discretised the stochastic differential equation (10) would become a low order ARMA type process of the kind reported in Wolff (1987) and Cheung (1993). The parameters in equation (10) may be estimated from the data using the Kalman filter as pointed out earlier.

Considering we have one forward price, $f(t, x)$, then we have a system of 3 stochastic differential equations. These are (under the measure Q)

$$
\begin{aligned}
& \mathrm{dS}=\left(\mathrm{r}-\mathrm{r}_{\mathrm{f}}+\lambda \sigma_{\mathrm{S}}\right) \mathrm{Sdt}+\sigma_{\mathrm{S}} \mathrm{SdW}(\mathrm{t}), \\
& \mathrm{d} \lambda=\kappa(\bar{\lambda}-\lambda) \mathrm{dt}+\sigma_{\lambda} \mathrm{dW}(\mathrm{t}), \\
& \mathrm{dF}(\mathrm{t}, \mathrm{x})=\left(\mathrm{r}-\mathrm{r}_{\mathrm{f}}+\lambda \sigma_{\mathrm{S}}\right) \mathrm{F}(\mathrm{t}, \mathrm{x}) \mathrm{dt}+\sigma_{\mathrm{S}} \mathrm{F}(\mathrm{t}, \mathrm{x}) \mathrm{dW}(\mathrm{t}),
\end{aligned}
$$

where, $\mathrm{S}(0)=\mathrm{S}_{0}, \lambda(0)=\lambda_{0}, \mathrm{f}(0, \mathrm{x})=\mathrm{S}_{0} \mathrm{e}^{\left(\mathrm{r}-\mathrm{r}_{\mathrm{f}}\right) \mathrm{x}}$.

It should be noted that the information contained in equations (11a) - (11c) is also contained in the pricing relationships,

$$
F(t, x)=S_{t} e^{\left(r-r_{f}\right) x}
$$

To estimate the parameters in the filtering framework, however, it is convenient to work with the equation (11c).

From equation (3), we can write the spot price at time $t+x$ as, using $s(t)=\ln S(t)$, as

$$
\mathrm{s}(\mathrm{t}+\mathrm{x})=\mathrm{s}(\mathrm{t})+\left(\mathrm{r}-\mathrm{r}_{\mathrm{f}}-\frac{\sigma_{\mathrm{s}}^{2}}{2}\right) \mathrm{x}+\sigma_{\mathrm{s}} \int_{\mathrm{t}}^{\mathrm{t}+\mathrm{x}} \lambda(\tau) \mathrm{d} \tau+\sigma_{\mathrm{s}} \int_{\mathrm{t}}^{\mathrm{t}+\mathrm{x}} \mathrm{dW}(\tau)
$$

From equation (13) we can write the expected value of $s(t+x)$ as 


$$
E_{t}[s(t+x)]=s_{t}+\left(r-r_{f}-\frac{\sigma_{S}^{2}}{2}\right) x+\sigma_{s} E_{t}\left[\int_{t}^{t+x} \lambda(\tau) d \tau\right]
$$

The derivation of this expectation may be found in Bhar, Chiarella and Pham (2001). It turns out to be:

$$
E_{t}[s(t+x)]=s(t)+\left(r-r_{f}-\frac{\sigma_{s}^{2}}{2}\right) x+\sigma_{s}\left[(\lambda(t)-\bar{\lambda})\left(\frac{1-e^{-k x}}{\kappa}\right)+\bar{\lambda} x\right]
$$

The above equation may also be expressed (via use of equation (7)) as,

$$
E_{t}[s(t+x)]=f(t, x)-\frac{\sigma_{s}^{2}}{2}+\sigma_{s}\left[(\lambda(t)-\bar{\lambda})\left(\frac{1-e^{-\kappa x}}{\kappa}\right)+\bar{\lambda} x\right]
$$

Let $\pi(\mathrm{t}, \mathrm{x})$ represent the risk premium (under $\mathrm{Q}$ ) for the $\mathrm{x}$ period ahead spot rate, then from equation (16)

$$
\pi(t, x)=-\frac{\sigma_{s}^{2}}{2}+\sigma_{s}\left[(\lambda(t)-\bar{\lambda})\left(\frac{1-\mathrm{e}^{-\kappa x}}{\kappa}\right)+\bar{\lambda} x\right]
$$

It has been pointed out that previous studies attributed the difference between the forward rate and the subsequently realised spot exchange rate to a risk premium and the unexpected depreciation of the exchange rate. Equation (17) gives an explicit expression for the risk premium, characterising how the market price of risk enters the expectation formation and thus influence the risk premium. The integral terms involving the Wiener increments in equation (13) may be related to the noise terms identified in Wolff (1987) and Cheung (1993).

In order to compute the time variation of risk premia for one-month forward rates obtained from equation (17) for a given exchange rate, we need the estimates of the parameters describing the stochastic process for $\lambda$ given by equation (10). Bhar, Chiarella and Pham (2001) show the state space formulation of the system and estimation of these parameters as well as the filtered and smoothed estimates of $\lambda(t)$. They also point out that 
this method can be easily applied to multiple forward exchange rates and thereby examine the term structure of forward risk premia present in the quoted forward exchange rates.

In this review article, we would also like to compare this with the risk premia obtained from the approach outlined in Wolff (1987) and Cheung (1993). Both these methods require data synchronisation with respect to matching the forward rate period. This is not necessary in the method just outlined above.

In the following section we also briefly describe the method of Wolff/Cheung so as to facilitate comparison with the above approach.

\section{Approach Based on Wolff (1987)/Cheung (1993)}

The main idea in modelling the forward exchange rate risk premia in their model is the assumption that the forecast error resulting from the forward rate as the predictor of futures spot exchange rate consists of a premium component and a white noise error. In this context,

$$
\mathrm{S}_{\mathrm{t}+1}=\mathrm{F}_{\mathrm{t}, \mathrm{t}+1}+\mathrm{P}_{\mathrm{t}}+\varepsilon_{\mathrm{t}}
$$

Here $\varepsilon_{\mathrm{t}}$ is an uncorrelated zero-mean sequence and $\mathrm{P}_{\mathrm{t}}$ is the unobserved risk premium. In terms of state space system representation this is the measurement equation. Both Wolff and Cheung determine the dynamic of the risk premium by studying the time series properties (in the Box-Jenkins sense) of the quantity $\left(\mathrm{F}_{\mathrm{t}, \mathrm{t}+1}-\mathrm{S}_{\mathrm{t}+1}\right)$. As suggested in Wolff (2000) for most currencies either an ARMA $(1,1)$ or an MA(1) representation is adequate. The corresponding equations for $\mathrm{P}_{\mathrm{t}}$ are given by,

$$
\begin{aligned}
& \mathrm{P}_{\mathrm{t}}=\phi \mathrm{P}_{\mathrm{t}-1}+\vartheta_{\mathrm{t}}(\operatorname{AR}(1)) \\
& \mathrm{P}_{\mathrm{t}}=\phi \mathrm{P}_{\mathrm{t}-1}+\theta \vartheta_{\mathrm{t}-1}+\vartheta_{\mathrm{t}}(\operatorname{ARMA}(1,1)) \\
& \mathrm{P}_{\mathrm{t}}=\theta \vartheta_{\mathrm{t}-1}+\vartheta_{\mathrm{t}}(\mathrm{MA}(1))
\end{aligned}
$$

It is straightforward to set up the state equation matrices with the above assumed dynamics of the unobserved risk premium. Assuming $v^{2}$ is the variance of the 
innovation $\vartheta$ the state space representation is given below. The estimation algorithm for these models is straightforward linear Kalman filter and same as for BCP (2001) model.

For AR (1) specification the measurement equation is (18) and the state equation is (19). For ARMA $(1,1)$ specification the state equation is:

$$
\left[\begin{array}{c}
\mathrm{P}_{\mathrm{t}} \\
\theta \vartheta_{\mathrm{t}}
\end{array}\right]=\left[\begin{array}{ll}
\phi & 1 \\
0 & 0
\end{array}\right]\left[\begin{array}{c}
\mathrm{P}_{\mathrm{t}-1} \\
\theta \vartheta_{\mathrm{t}-1}
\end{array}\right]+\left[\begin{array}{l}
1 \\
\theta
\end{array}\right] \vartheta_{\mathrm{t}},
$$

and the measurement equation takes the form:

$$
\mathrm{S}_{\mathrm{t}+1}=\mathrm{F}_{\mathrm{t}, \mathrm{t}+1}+\left[\begin{array}{ll}
1 & 0
\end{array}\right]\left[\begin{array}{c}
\mathrm{P}_{\mathrm{t}} \\
\theta \vartheta_{\mathrm{t}}
\end{array}\right]+\varepsilon_{\mathrm{t}}
$$

For the MA(1) representation the matrices are similar to that in case of $\operatorname{ARMA}(1,1)$ with restriction that $\phi=0$.

\section{Data and Empirical Results}

As part of our empirical investigation we apply both the methodologies reviewed here to five different exchange rates, all against U.S. dollars. We restrict ourselves to the pre-Euro era. These are Australian dollar (AUD), German marks (DEM), French frank (FRF), British pound (GBP) and the Japanese yen (JPY). The data set covers the period January 1986 to December 1998 with 156 observations in each series. We use only the one-month forward exchange rates so that the results from the BCP model can be compared directly with those from the implementation of Wolff/Cheung methodology. It should be pointed out that the BCP methodology does not require that the observations should be properly aligned with the maturity of the forward rates. The exchange rate data reflects the daily 4PM London quotation obtained from DataStream ${ }^{\mathrm{TM}}$ and the interest rate data are the daily closing onemonth Euro currency deposit rates.

To start the adaptive algorithm of the Kalman filter we initialise the state vector with the first observations. The algorithm also requires specifying the prior covariance matrix for the state vector. In the absence of any specific knowledge about the prior distribution we use the diffuse prior specification following Harvey (1989, p. 121). 
The parameter estimates are obtained by maximising the log likelihood function discussed in detail in BCP (2001). The numerical optimisation algorithm called 'Newton' in GAUSS $^{\mathrm{TM}}$ is used for this purpose without any parameter constraints. The results of the estimation procedure are shown in Table 1 . The t-statistics reported in that table are computed from the standard error obtained from the heteroscedasticity consistent covariance matrix of the parameters at the point of convergence.

All the parameters of the model except the long-term average market price of risk are statistically significant for each of the currencies. The estimated parameter $\sigma_{\mathrm{s}}$ compares favourably with the sample estimates obtained from the spot exchange rate series (not reported separately). How the model fits the data is best analysed by examining the residual from the estimation process. These are reported in Table 2. One of the main requirements is that the residual be serially uncorrelated both in its level and its squared form. The portmanteau test and the ARCH test support this requirement for all the currencies examined. As the Kalman filter generated residuals are recursive in nature two other tests are carried out to judge the model adequacy. These are modified Von Neumann ratio and the recursive ttests (see Harvey (1990), page 157). Both these tests support our modelling approach. Finally, the conditional normality assumption made in the modelling is also supported by the Kolmogorov-Smirnov test statistics reported in Table 2.

Since we are interested in comparing and contrasting the two modelling approaches we present the estimation results of the Wolff/Cheung models for the same set of currencies in Table 3. As can be seen most parameters are statistically significant. We subject the model residuals to the same set of tests as in Table 2 (although in their original papers, Wolff/Cheung does not report these diagnostics). The results reported in Table 4 support all the model adequacy tests.

For the BCP model the risk premia contained in the one-month forward exchange rate can be computed easily from equation (17) with the help of the estimated parameters from Table 1 and the filtered (or smoothed) estimates of the market price of risk. Since Wolff/Cheung method does not provide this risk premia directly we dot not analyse this aspect any further.

Next, we compare the one-month ahead prediction of the spot exchange rate with the realised exchange rate and thus generate the mean absolute prediction error and the root mean squared prediction error for each of the exchange rate series. In the context of Kalman filter this is really ex ante prediction error since the prediction of the measurement variable for 
time $\mathrm{t}+1$ is made utilising information up to and including time $t$. This is true for Wolff/Cheung model as well because the way we have implemented it. The comparative results are shown in Table 5 for our model, Wolff/Cheung model as well as a martingale process.

Overall conclusion from examining the Table 5 is that both the models perform better than the martingale process. There is, however, not much difference in forecasting performance between the BCP model and Wolff/Cheung model. It should, however, be remembered that the BCP model could be implemented for data set of any observed frequency whereas Wolff/Cheung approach is limited to data set where the spot exchange rate frequency aligns with the forward rate data used.

\section{Conclusions}

In this paper we have reviewed two approaches to analyse the time varying risk premium in forward exchange rates. The first one, the BCP model exploits the relationship that links the spot exchange rate and the forward exchange rate through the market price of risk. By directly modelling the market price of risk as a mean reverting process it is possible to show how the market price of risk enters into expectation formation for a future spot exchange rate.

This BCP methodology allows us to quantify the risk premium associated with a particular forward exchange rate in terms of the parameters of the process describing the market price of risk. We also discuss how these parameters can be estimated in a state space framework by application of Kalman filter. This procedure, in turn, generates the filtered and the smoothed estimates for the unobserved market price of risk.

The second methodology i.e. Wolff/Cheung procedure is also applied to the same data set and for three different dynamics of the unobserved risk premium process. This model is also estimated via Kalman filter.

Both these models perform well in one step ahead forecasting spot exchange rate and both beat the naïve forecast. However, the BCP model is well suited for any observed data frequency, whereas in the Wolff/Cheung method spot and forward exchange rate data frequency needs to be matched. 


\section{References:}

Backus, D., Gregory, A. and Telmer, C. (1993), “Accounting for forward rates in markets for foreign currency”, Journal of Finance, 48, 1887-1908.

Bakshi, G.S. and Naka, A. (1997), "Unbiasedness of the forward exchange rates”, The Financial Review, 32(1), 145-162.

Bekaert, G. (1994), "Exchange rate volatility and deviation from unbiasedness in a cash-inadvance model”, Journal of International Economics, 36, 29-52.

Bhar, R., Chiarella, C. and Pham, T (2001), "Modelling the Currency Forward Risk Premium: A New Perspective”, Asia-Pacific Financial Markets, December 2001, 8(4), 341-360.

Cheung, Y. (1993), “Exchange rate risk premiums”, Journal of International Money and Finance, 12, 182-194.

Engel, C. (1996), “The forward discount anomaly and the risk premium: A survey of recent evidence”, Journal of Empirical Finance, 3, 123-192.

Harvey, A. C. (1989), Forecasting structural time series models and the Kalman filter, Cambridge University Press, Cambridge.

Harvey, A. C., 1990. The Econometric Analysis of Time Series, $2^{\text {nd }}$ edition. Cambridge, Massachusetts: The MIT Press.

Hull, J. C. (1997), Options, Futures, and Other Derivatives, Third Edition, Prentice Hall International Inc.

Lucas, R. E. (1982), “Interest rates and currency prices in a two country world”, Journal of Monetary Economics, 10, 335-360.

Phillips, P. C. B. and Mcfarland, J. W. (1997), "Forward exchange market unbiasedness: the case of Australian dollar since 1984”, Journal of International Money and Finance, $16,885-907$.

Wells, C. (1996), The Kalman Filter in Finance, Kluwer Academic Publishers.

Wolff, C. C. P. (1987), "Forward foreign exchange rates, expected spot rates, and premia: A signal-extraction approach”, The Journal of Finance, XLII (2), 395-406.

Wolff, C. C. P. (2000), "Measuring the forward exchange risk premium: multi-country evidence from unobserved component models", Journal of International Financial markets, Institutions and Money, 10, 1-8.

Wu, Y. and Zhang, H. (1997), "Forward premiums as unbiased predictors of future currency depreciation: a non-parametric analysis”, Journal of International Money and Finance, 16, 609-623. 
Table 1

Parameter Estimates for the Model Based on Market Price of Risk

\begin{tabular}{lcccc}
\hline & $\sigma_{\mathrm{S}}$ & $\kappa$ & $\bar{\lambda}$ & $\sigma_{\lambda}$ \\
\cline { 2 - 5 } & & & & \\
Australian Dollar (AUD) & 0.0272 & 8.0884 & 0.7226 & 21.2137 \\
& $(2.16)$ & $(2.81)$ & $(0.68)$ & $(2.16)$ \\
German Mark (DEM) & 0.0797 & 17.8281 & -0.2457 & 6.0437 \\
& $(9.48)$ & $(7.88)$ & $(-0.67)$ & $(2.98)$ \\
French Franc (FRF) & 0.0528 & 11.2577 & -0.5531 & 13.2373 \\
& $(3.45)$ & $(5.97)$ & $(-0.80)$ & $(2.58)$ \\
British Pound (GBP) & 0.0609 & 12.2235 & -0.6545 & 11.8079 \\
& $(5.12)$ & $(5.85)$ & $(-1.12)$ & $(4.54)$ \\
Japanese Yen (JPY) & 0.0960 & 9.3827 & 0.0590 & 4.3061 \\
& $(6.79)$ & $(0.98)$ & $(0.27)$ & $(2.15)$ \\
\hline
\end{tabular}

Numbers in parentheses are t-statistics computed from standard errors obtained using the heteroscedasticity consistent covariance matrix at the point of convergence.

Table 2

Residual Diagnostics and Model Adequacy Tests (Model in Table 1)

\begin{tabular}{cccccc}
\hline Market & Portmanteau & ARCH & MNR & Recursive T & KS Statistic \\
\hline & & & & & \\
AUD & 0.226 & 0.702 & 0.832 & 0.597 & 0.042 \\
DEM & 0.080 & 0.474 & 0.996 & 0.887 & 0.055 \\
FRF & 0.482 & 0.494 & 0.871 & 0.917 & 0.082 \\
GBP & 0.091 & 0.342 & 0.897 & 0.857 & 0.068 \\
JPY & 0.286 & 0.608 & 0.600 & 0.956 & 0.064 \\
\hline
\end{tabular}

Entries are p-values for the respective statistics except for the KS statistic. These diagnostics are computed from the recursive residual of the measurement equation, which corresponds to the spot index process. The null hypothesis in portmanteau test is that the residuals are serially uncorrelated. The ARCH test checks for no serial correlations in the squared residual up to lag 26. Both these test are applicable to recursive residuals as explained in Wells (1996, page 27). MNR is the modified Von Neumann ratio test using recursive residual for model adequacy (see Harvey (1990, chapter 5). Similarly, if the model is correctly specified then Recursive T has a Student's t-distribution (see Harvey (1990, page 157). KS statistic represents the Kolmogorov-Smirnov test statistic for normality. 95\% significance level in this test is 0.109 . When KS statistic is less than 0.109 the null hypothesis of normality cannot be rejected. 
Table 3

Parameter Estimates for the Model Based on Wolff (1986), Cheung (1993)

\begin{tabular}{lcccc}
\hline & $\phi$ & $\theta$ & $\varepsilon$ & $\nu$ \\
\cline { 2 - 5 } Australian Dollar (AUD) & & & & \\
& 0.9439 & & 0.0261 & 0.0000 \\
German Mark (DEM) & $(23.18)$ & & $(17.01)$ & $(0.000)$ \\
& -0.7150 & 0.9206 & 0.0142 & 0.0277 \\
French Franc (FRF) & $(-6.57)$ & $(5.12)$ & $(1.64)$ & $(4.28)$ \\
& -0.7183 & 0.9189 & 0.0077 & 0.0288 \\
British Pound (GBP) & $(-7.40)$ & $(9.70)$ & $(5.56)$ & $(15.31)$ \\
& & 0.6318 & 0.0269 & 0.0159 \\
Japanese Yen (JPY) & & $(5.90)$ & $(6.14)$ & $(2.25)$ \\
& & 0.9311 & 0.0368 & 0.0054 \\
& & $(3.91)$ & $(10.27)$ & $(0.57)$ \\
\hline
\end{tabular}

Numbers in parentheses are t-statistics computed from standard errors obtained using the heteroscedasticity consistent covariance matrix at the point of convergence.

\section{Table 4}

Residual Diagnostics and Model Adequacy Tests (Model in Table 3)

\begin{tabular}{cccccc}
\hline Market & Portmanteau & ARCH & MNR & Recursive T & KS Statistic \\
\hline & & & & & \\
AUD & 0.130 & 0.769 & 0.297 & 0.925 & 0.035 \\
DEM & 0.428 & 0.938 & 0.604 & 0.482 & 0.055 \\
FRF & 0.591 & 0.937 & 0.379 & 0.275 & 0.059 \\
GBP & 0.270 & 0.420 & 0.486 & 0.287 & 0.083 \\
JPY & 0.458 & 0.551 & 0.539 & 0.942 & 0.063 \\
\hline
\end{tabular}

Entries are p-values for the respective statistics except for the KS statistic. These diagnostics are computed from the recursive residual of the measurement equation, which corresponds to the spot index process. The null hypothesis in portmanteau test is that the residuals are serially uncorrelated. The ARCH test checks for no serial correlations in the squared residual up to lag 26. Both these test are applicable to recursive residuals as explained in Wells (1996, page 27). MNR is the modified Von Neumann ratio test using recursive residual for model adequacy (see Harvey (1990, chapter 5). Similarly, if the model is correctly specified then Recursive T has a Student's t-distribution (see Harvey (1990, page 157). KS statistic represents the Kolmogorov-Smirnov test statistic for normality. 95\% significance level in this test is 0.109 . When KS statistic is less than 0.109 the null hypothesis of normality cannot be rejected. 
Table 5

One Step Ahead Forecast Error for Spot Exchange Rate

\begin{tabular}{llcc}
\hline \multicolumn{1}{c}{ Model Based on } & MAE \\
\cline { 2 - 3 } AUD & Market Price of Risk & 0.0205 & 0.0007 \\
& Cheung/Wolff & 0.0206 & 0.0007 \\
& Martingale Process & 0.0279 & 0.0013 \\
DEM & Market Price of Risk & & 0.0011 \\
& Cheung/Wolff & 0.0258 & 0.0010 \\
FRF & Martingale Process & 0.0254 & 0.0035 \\
& Market Price of Risk & 0.0451 & 0.0010 \\
& Cheung/Wolff & & 0.0009 \\
GBP & Martingale Process & 0.0248 & 0.0344 \\
& Market Price of Risk & 0.0241 & 0.0010 \\
& Cheung/Wolff & 0.1446 & 0.0011 \\
& Martingale Process & & 0.0004 \\
& Market Price of Risk & 0.0235 & 0.0014 \\
& Cheung/Wolff & 0.0250 & 0.0014 \\
& Martingale Process & 0.0143 & 23.5860 \\
\end{tabular}

'MAE' and 'MSE' represent mean absolute error and mean squared error respectively. These are computed from the one step ahead forecast error obtained during Kalman filter recursion. These forecast errors are used to develop the prediction error form of the likelihood function. Cheung/Wolff model refers to our somewhat modified implementation of their approach. 